\title{
Humanização e Formação Médica: Cuidando da Saúde Mental do Estudante de Medicina
}

\author{
Nóbrega, Simone da; Moreira, Tomaz; Dutra, Elza Maria Socorro \\ UFM — simonetomaz@hotmail.com
}

Introdução: a formação médica expõe os estudantes a fontes de tensão desde o processo de admissão até o final da graduação. Diante dessa realidade, os estudantes se encontram mais vulneráveis ao suicídio, à depressão, ao uso de drogas, podendo, inclusive, prejudicar a construção da sua identidade profissional, como também o cuidado que terá com o paciente. Objetivo: estimar a prevalência do estresse, da depressão e da ideação suicida entre estudantes de medicina Métodos: Estudo transversal, com abordagem metodológica quantitativa, tendo participado do estudo 175 sujeitos distribuídos equitativamente entre os diferentes períodos do curso. Foram utilizados os seguintes instrumentos: Inventário de Depressão (BDI), a Escala de Ideação Suicida (BSI) e o Inventário de Sintomas de Stress de Lipp (ISSL). a análise estatística compreendeu a utilização dos testes ' $t$ ' de student e qui-quadrado. o nível de significância adotado foi de 5\%. Resultados: dos estudantes entrevistados, a maioria (58\%) estava compreendida entre 20 e 25 anos. Os resultados do BDI mostraram que 115 alunos apresentaram um nível Mínimo de depressão; 48, nível Leve, 10 Moderado e 2 Grave. o BSI mostrou Presença de Ideação: 14 (8\%) e Ausência de Ideação: 161 (92\%). no LIPP, a maioria dos estudantes apresentou estresse (62\%). Desses, $3 \%$ se encontraram na fase de alerta, $50 \%$ na fase de resistência, $5 \%$ na fase de quase-exaustão, $4 \%$ na fase exaustão. a sintomatologia predominante foi a psicológica (45\%). Conclusão: Os resultados evidenciaram um nível significativo de estresse entre os estudantes, confirmando estudos que apontam a sobrecarga de trabalho, necessidade de adaptação ao universo acadêmico e a natureza do curso, que lida com dor, vida e morte, como fatores estressores. Os resultados subsidiarão a implementação de estratégias de prevenção do suicídio, do estresse e da depressão, por meio de serviços de assistência psicológica aos estudantes, contribuindo para uma prática médica humanizada.

Nóbrega, Simone da; Moreira, Tomaz; Dutra, Elza Maria Socorro. Humanização e Formação Médica: Cuidando da Saúde Mental do Estudante de Medicina. In: Anais do Congresso Internacional de Humanidades \& Humanização em Saúde [= Blucher Medical Proceedings, num.2, vol.1]. São Paulo: Editora Blucher, 2014. ISSN 2357-7282

DOI 10.5151/medpro-cihhs-10369 